\title{
Skin Cancer in the US Military
}

\author{
Ryan Gall, MD; Michelle Bongiorno, MD; Kent Handfield, MD, MPH
}

\section{PRACTICE POINTS}

- An increased risk for melanoma and keratinocyte carcinomas has been identified in those who have served in the US Military.

- UV radiation exposure, low utilization of sunprotective strategies, and low overall education regarding the risks of UV exposure appear to be the primary contributors to increased risks of skin cancer in this population.

- Improving education for military servicemembers on the risks of UV exposure, increasing utilization of sun-protective clothing, and improving access and utilization of sunscreen are viable options to decrease the risk for cutaneous malignancies in US Military servicemembers.

There is an increased risk for melanomas and keratinocyte cancers in those who have served on active duty in the US Military. We believe that an increased exposure to UV radiation, minimal sun-protective strategies, and a paucity of education regarding the risks of UV exposure are primarily responsible for the increased prevalence of skin cancer in this population. Although mitigating these risks is important, it cannot come at the expense of combat effectiveness and military mission readiness. This review proposes education of individual military servicemembers regarding skin cancer prevention and identification, increasing the utilization of sunprotective clothing, and promoting the increased use of sunscreen as measures to decrease the overall risk of cutaneous malignancies in US Military servicemembers.

Cutis. 2021;107:29-33.
7 here are numerous intrinsic risks that military servicemembers face, such as the dangers of combat, handling firearms, operating ships and heavy machinery, undersea diving, and aircraft operations. Multiple studies also have identified an increased risk for melanomas and keratinocyte cancers in those who have served on active duty.

\section{Epidemiology}

Differences in demographics are important to consider given the differences among races in the risks of skin cancers. Important racial demographic differences exist between the US Military and the general US population. Racial demographic differences also exist among the various military branches themselves. The US population is $61.0 \%$ White, $20.7 \%$ racial minorities (defined as Black or African American, Asian, American Indian or Alaska native, Native Hawaiian or other Pacific Islander, multiracial, or unknown), and $18.3 \%$ Hispanic or Latino (Hispanic or Latino was not listed as a component of racial minorities). ${ }^{1}$ According to 2018 data, the US Military population is $52.9 \%$ White, $31.0 \%$ racial minorities, and $16.1 \%$ Hispanic or Latino. $^{2}$ The percentage of White military members was highest in the US Marine Corps (58.4\%) and lowest in the US Navy (46.5\%). The percentage of racial minorities was highest in the US Navy (38.0\%) and lowest in the US Marine Corps (20.0\%). ${ }^{2}$ The percentage of Hispanic and Latino military members was highest in the US Marine Corps (21.6\%) and lowest in the US Air Force $(14.5 \%){ }^{2}$

\footnotetext{
Dr. Gall is from the National Capital Consortium Transitional Year Internship, Bethesda, Maryland. Drs. Bongiorno and Handfield are from the Department of Dermatology, Walter Reed National Military Medical Center, Bethesda.

The authors report no conflict of interest.

The views expressed in this article are those of the authors and do not reflect the official position of the institution, the Departments of the Navy/ Army/Air Force, the Department of Defense, or the US Government.

Correspondence: Ryan Gall, MD, 5200 Crossfield Ct, Unit \#9, North Bethesda, MD 20852 (ryan.gall.md@gmail.com). doi:10.12788/cutis.0153
} 


\section{Melanoma in Military Members}

It is estimated that the annual incidence rate of melanoma in the United States is 27 per 100,000 individuals for non-Hispanic Whites, 5 per 100,000 for Hispanics, and 1 per 100,000 for Black individuals and Asians/Pacific Islanders. ${ }^{3}$ Three studies have reviewed melanoma incidence in relation to service in the US Military.

A 2011 retrospective tumor registries study of US veterans aged 45 years or older demonstrated increased incidences of melanoma compared with the general population. ${ }^{4}$ With age, the melanoma incidence per 100,000 person-years increased in White veterans compared to their civilian counterparts (aged 45 to 49 years, 33.62 vs 27.49; aged 50 to 54 years, 49.76 vs 32.18; aged 55 to 59 years, 178.48 vs 39.17). ${ }^{4}$ An increased melanoma incidence of $62 \%$ also was seen in activeduty servicemembers aged 18 to 56 years compared to their age-matched civilian peers in a 2014 retrospective cohort study. ${ }^{5}$

Melanoma rates also vary depending on military service branch. Across 3 separate studies, service in the US Air Force was associated with the highest risk for melanoma development. A surveillance report of cancer incidence in active-duty US Armed Forces personnel between 2000 and 2011 conducted by the Defense Medical Surveillance System showed an incidence rate (per 100,000 person-years) for melanoma of 10.5 in all services, and a rate of 15.5 in the US Air Force vs 8.6 in the US Army, further highlighting the disparity between the services. ${ }^{6}$ The 2014 study also demonstrated a melanoma incidence rate of 17.80 in active-duty US Air Force personnel compared to 9.53 in active-duty US Army personnel. ${ }^{5}$ Among US Air Force active-duty personnel, one study showed a melanoma incidence rate (per 100,000 person-years) of 7.59 for men and 8.98 for women compared to 6.25 and 5.46, respectively, in US Army soldiers. ${ }^{4}$

\section{Keratinocyte Cancers in Military Members}

Although less well studied than melanoma, keratinocytederived skin cancers represent a major source of disease burden both during and after active-duty service. In a retrospective chart review of dermatology patients seen at the 86th Combat Support Hospital at Ibn Sina Hospital in Baghdad, Iraq, during a 6-month period in $2008,8 \%$ of 2696 total visits were identified to be due to skin cancer, with the overwhelming majority being for keratinocyte cancers. ${ }^{7}$ A 1993 retrospective chart review of World War II veterans referred for Mohs micrographic surgery showed a considerably higher incidence in those who served in the Pacific Theater compared to those who served in the European Theater. Despite having approximately equal characteristics - age, skin type, and cumulative time spent outdoors-between the 2 groups, military servicemembers deployed to the Pacific represented 66\% of the patients with basal cell carcinoma and $68 \%$ of the patients with squamous cell carcinoma. ${ }^{8}$

\section{Contributing Factors}

There are many factors related to military service that are likely to contribute to the increased risk for skin cancer. Based on a review of the literature, we have found an increased exposure to UV radiation, low utilization of sun-protective strategies, and low overall education regarding the risks for UV exposure to be the primary contributors to increased risks for skin cancer.

UV exposure is the primary mitigatable risk factor for developing melanoma and keratinocyte cancers. ${ }^{9,10}$ In a 2015 study of 212 military servicemembers returning from deployments in Iraq and Afghanistan, 77\% reported spending more than 4 hours per day working directly in the bright sun, with $64 \%$ spending more than $75 \%$ of the average day in the bright sun. ${ }^{11}$ A 1984 study of World War II veterans diagnosed with melanoma also showed that $34 \%$ of those with melanoma had prior deployments to the tropics compared to $6 \%$ in age-matched controls. ${ }^{12}$

Even in those not deployed to overseas locations, military work still frequently involves prolonged sun exposure. In a 2015 cross-sectional study of US Air Force maintenance squadrons at Travis Air Force Base in Fairfield, California ( $=356), 67 \%$ of those surveyed reported having careers that frequently involved direct sun exposure. ${ }^{13}$ This occupational sun exposure may be worsened by increased UV exposure during recreational activities, as active-duty military servicemembers may reasonably be expected to engage in more outdoor exercise and leisure activities than their civilian counterparts.

Other occupation-specific risk factors also may affect skin cancer rates in certain populations. In a study of aircraft personnel that included male military and civilian pilots, a meta-standardized incidence ratio for melanoma of 3.42 was identified compared to controls not involved in aircraft work. ${ }^{14}$ Theories to explain this increased incidence of melanoma include increased exposure to ionizing radiation at high altitudes, exposure to aviationrelated chemicals, and alterations in circadian rhythm. ${ }^{14,15}$

This increased sun exposure is compounded by the overall low rates of sun protection among military members. Of those returning from Iraq and Afghanistan in the 2015 study, less than 30\% of servicemembers reported routine access to sunscreen, and only 13\% stated that they routinely applied sunscreen when exposed to the sun. Of this same group, only $23 \%$ endorsed that the military made them very aware of their risk for skin cancer. ${ }^{11}$ The low rates of sunscreen usage by those deployed to an active combat zone may partially be explained by the assumption that those individuals placed more emphasis on the acute dangers of combat rather than the perceived future dangers of skin cancer. A decreased availability of sunscreen for deployed military servicemembers, particularly those located at small austere bases where supplies are likely to be limited, likely makes the use of sunscreen even more difficult.

However, even within the continental United States, active-duty military servicemembers still exhibit low rates 
of sunscreen usage. In the 2015 study of US Air Force personnel in maintenance squadrons in California, less than $11 \%$ of those surveyed reported using sunscreen most of the time despite high rates of outdoor work..$^{13}$

Another factor likely contributing to increased sun exposure and decreased sun-protection practices is the so-called invincibility complex, which is a common set of egocentric beliefs that leads to a perception that an individual is not likely to suffer the consequences of engaging in risky behaviors. Despite knowledge of the dangers associated with risky activity, individuals with an invincibility complex are more likely to view potential consequences as relevant only to others, not to themselves. ${ }^{16}$ A study of adolescent smokers in the Netherlands examined why subjects continue to smoke, despite knowledge of the potentially deadly consequences of smoking. Three common rationalizing beliefs were found: trivialization of the immediate consequences, that their smoking is only temporary and they have time in the future to stop, and that they have control over how much they smoke and can prevent fatal consequences with moderation. ${ }^{17}$ Such an invincibility complex is thought to directly run counter to the efforts of public health and educational campaigns. This belief set is thought to at least partially explain why adolescents in Australia are the most knowledgeable age cohort regarding the dangers of UV exposure but the least likely to engage in skin-protective measures. ${ }^{18}$ This inflated sense of invincibility may be leading activeduty military servicemembers to engage in unhealthy sun-exposure practices regardless of knowledge of the associated risks.

Members of the military may be uniquely susceptible to this invincibility complex. Growing evidence suggests that exposure to life-threatening circumstances may lead to long-lasting alterations in threat assessment. ${ }^{19,20}$ A 2008 study of Iraq veterans returning from deployment found that direct exposure to violent combat and human trauma was associated with an increased perceived degree of invincibility and a higher propensity to engage in risky behaviors after returning from deployment. ${ }^{19}$ Additionally, it has been speculated that individuals with a higher degree of perceived invincibility may be more likely to pursue military service, as a higher degree of self-confidence in the face of the often dangerous circumstances of military operations may be advantageous. ${ }^{20}$

In addition to scarce use of sun-protective strategies, military servicemembers also tend to lack awareness of the potential short-term and long-term harm from UV radiation. In a 2016 study of veterans undergoing treatment for skin cancer, patients reported inadequate education about skin cancer risks and strategies to decrease their chances of developing it. ${ }^{21}$ Sunscreen is less frequently used in males, specifically those aged 18 to 30 years; this demographic makes up $55.7 \%$ of the activeduty population. ${ }^{2,22}$ Low income also has been associated with decreased sunscreen use; junior enlisted military servicemembers (ranks E1-E4) make up $43.8 \%$ of the military's ranks and make less than the average annual American household income. ${ }^{2,23,24}$

\section{Prevention and Risk-Mitigation Strategies}

Although many of the risk factors in the US Military promoting skin cancer are intrinsic to the occupation, certain steps could help minimize servicemembers' risks. To be effective, any attempt to decrease the risk for skin cancer in the US Military must take into consideration the environment in which the military operates. To complete their mission, military personnel often are required to operate for extended periods outdoors in areas of high UV exposure, such as the deserts of Iraq or the mountains of Afghanistan. Outdoor work at times of peak sunlight often is required for successful mission completion, thus it would be ineffective to simply give blanket advice to avoid sun exposure.

Another important factor is the impact that official policy plays in shaping the daily actions of individual military servicemembers. In a hierarchical organization such as the US Military, unit commanders have substantial authority over the behaviors of their subordinates. Thus, strategies to mitigate skin cancer risks should be aimed at the individual servicemembers and unit commanders and at a policy level. Ultimately, a 3-pronged approach built on education, access to sun-protective gear, and increased availability to sunscreen is recommended.

Education-The foundation for any skin cancer prevention strategies should be built on the education of individual military servicemembers. The majority of active-duty members and veterans did not believe the military did enough to actively educate them on the risks for developing skin cancer. ${ }^{21}$ An effective educational program should focus on prevention and detection. Prevention programs should explain the role of UV exposure in the development of skin cancer, the intrinsic risks of UV exposure associated with outdoor activities, and strategies that can be implemented to reduce UV exposure and lifetime risk of skin cancer development. In a study of German outdoor workers, displays of support and concern by management regarding UV protection were associated with increases in sunprotective behaviors among the employees. ${ }^{25}$

Because patient self-examinations have been shown to be associated with earlier melanoma diagnosis and a more superficial depth at diagnosis, detection programs also should focus on the identification of suspicious skin lesions, such as by teaching the ABCDEs of melanoma. ${ }^{26}$ Among the general population, educational campaigns have been shown to be effective at reducing melanoma mortality. ${ }^{27,28}$

Access to Sun-Protective Gear-The second aspect of reducing skin cancer risk should be aiming to protect military servicemembers from UV exposure. Any prevention strategy must fit within the military's broader tactical and strategic framework. 
The use of photoprotective strategies rather than the outright avoidance of sun exposure should be implemented to minimize the deleterious effects of outdoor work. The most recent study of the UV-protective properties of US Military uniforms found all tested uniforms to have either very good or excellent UV protection, with UV protection factors (UPFs) ranging from 35 to $50+{ }^{29}$ However, this study was performed in 2002, and the majority of the uniforms tested are no longer in service. More up-to-date UPF information for existing military uniforms is not currently available. Most military commands wear baseball hat-style covers when operating outdoors, which generally provide good photoprotection with UPF ratings of 35 to 50 over the protected areas. ${ }^{29}$ Unfortunately, these types of headgear offer less photoprotection than do wide-brimmed hats, which have demonstrated improved photoprotection, particularly of the neck, cheeks, ears, and chin. ${ }^{30} \mathrm{~A}$ wide-brimmed hat, known as the boonie hat, was originally proposed for military use in 1966 to provide protection of servicemembers' faces and necks from the intense sun of Vietnam. Currently, the use of the boonie hat typically is prohibited for units not engaged in combat or combat-support roles and requires authorization by the unit-level commander. ${ }^{31}$ Because of its perception as"unmilitary appearing" by many unit commanders and its restriction of use to combat-related units, the boonie hat is not consistently used. Increasing the use of this type of wide-brimmed hat would be an important asset in decreasing chronic UV exposure in military servicemembers, particularly on those parts of the body where skin cancer occurrence is the greatest. ${ }^{32}$ Policies should be aimed at increasing the use of the boonie hat, both through expanding its availability to troops in noncombat-related fields and by encouraging unit commanders to authorize its use in their units.

Sunscreen Availability-Improving the use of sunscreen is another impactful strategy that could be undertaken to decrease the risk for skin cancer in military servicemembers. The use of sunscreen is low in both those deployed overseas and those stationed within the United States. Improving access to sunscreen, particularly in the deployed setting, also could reduce barriers to use. Providing sunscreen directly to servicemembers, either when issuing gear or integrated within Meals Ready to Eat, could remove both the financial and logistical barriers to sunscreen utilization. Centralized troop-gathering locations, such as dining facilities, could be utilized both for the mass distribution of sunscreen and to display educational material. Unit commanders also could mandate times for servicemembers to stop work and apply sunscreen at regularly scheduled intervals.

The composition and delivery vehicle of sunscreen may have an impact on its efficacy and ease of use in the field. The American Academy of Dermatology (AAD) recommends using sunscreen that is broad spectrum, sun protection factor (SPF) 30 or greater, and water resistant. ${ }^{33}$ However, the AAD does not make a recommendation of whether to use a physical sunscreen (such as titanium dioxide) or a chemical sunscreen. If applied in equal amounts, a chemical sunscreen and a physical sunscreen with an equal SPF should offer the same UV protection. However, a study in the British Journal of Dermatology showed that subjects applied only two-thirds the quantity of physical sunscreen compared to those applying chemical sunscreen, achieving approximately only one-half the SPF as provided by the chemical sunscreen. ${ }^{34}$ Because sunscreen is only effective when it is used, consideration should be given to the preferences of the military population when selecting sunscreens. A review of consumer preferences of sunscreen qualities showed that sunscreens that were nongreasy and did not leave a residue were given the most favorable rankings ${ }^{35}$ In recent years, sunscreen sprays have become increasingly popular. When adequately applied, sprays have been shown to be equally effective as sunscreen lotions. ${ }^{36}$ However, although recommendations have been issued by both the AAD and the US Food and Drug Administration on the application of sunscreen lotion to adequately cover exposed skin, no such recommendations have been given for sunscreen sprays. ${ }^{33}$ Some safety concerns also remain regarding the flammability of aerosol sunscreens, which could be exacerbated in a combat situation. ${ }^{37}$

However, there are some obvious downsides to sunscreen use. During certain operational tasks, particularly in combat settings, it may not be feasible or even safe to stop working to apply sunscreen at the 2-hour intervals required for effective UV protection. ${ }^{38}$ Water exposure or large amounts of perspiration also would cause sunscreen to lose effectiveness earlier than expected. Logistically, it may be challenging to regularly supply sunscreen to small austere bases in remote locations.

\section{Final Thoughts}

The men and women of our armed forces already undertake great risk in the defense of our country. It should be ensured that their risk for developing skin cancer is made as low as possible, while still allowing them to successfully accomplish their mission. Multiple studies have shown servicemembers to be at an increased risk for skin cancer, particularly melanoma. We believe the primary factor behind this increased risk is occupational UV exposure, which is compounded by the suboptimal use of sunprotective strategies. By educating our servicemembers about their risk for skin cancer and promoting increased UV protection, we can effectively reduce the burden of skin cancer on our active-duty servicemembers and veterans.

\section{REFERENCES}

1. QuickFacts. United States Census Bureau. Accessed December 15, 2020. https://www.census.gov/quickfacts/fact/table/US/PST045219

2. 2018 Demographics Profile. Military OneSource. Accessed December 15, 2020. https://www.militaryonesource.mil/reports-and -surveys/infographics/active-duty-member-and-family-demographics

3. Cancer Facts \& Figures 2019. American Cancer Society. Accessed December 15, 2020. https://www.cancer.org/research/cancer-facts -statistics/all-cancer-facts-figures/cancer-facts-figures-2019.html 
4. Zhou J, Enewold L, Zahm SH, et al. Melanoma incidence rates among whites in the U.S. Military. Cancer Epidemiol. 2011;20:318-323.

5. Lea CS, Efird JT, Toland AE, et al. Melanoma incidence rates in active duty military personnel compared with a population-based registry in the United States, 2000-2007. Military Med. 2014;179:247-253.

6. Armed Forces Health Surveillance Center. Incident diagnoses of cancers and cancer-related deaths, active component, US Armed Forces, 2000-2011. MSMR. 2012;19:18-22

7. Henning JS, Firoz BF. Combat dermatology: the prevalence of skin disease in a deployed dermatology clinic in Iraq. J Drugs Dermatol. 2010;9:210-214

8. Ramani ML, Bennett RG. High prevalence of skin-cancer in WorldWar-II servicemen stationed in the Pacific Theater. J Am Acad Dermatol. 1993;28:733-737.

9. Schmitt J, Seidler A, Diepgen TL, et al. Occupational ultraviolet light exposure increases the risk for the development of cutaneous squamous cell carcinoma: a systematic review and meta-analysis. $\mathrm{Br} \mathrm{J}$ Dermatol. 2011;164:291-307.

10. Armstrong BK, Kricker A. The epidemiology of UV induced skin cancer. J Photochem Photobiol B. 2001;63:8-18.

11. Powers JG, Patel NA, Powers EM, et al. Skin cancer risk factors and preventative behaviors among United States military veterans deployed to Iraq and Afghanistan. J Invest Dermatol. 2015;135:2871-2873.

12. Brown J, Kopf AW, Rica DS, et al. Malignant melanoma in World War II veterans. Int J Dermatol. 1984;23:661-663.

13. Parker G, Williams B, Driggers P. Sun exposure knowledge and practices survey of maintenance squadrons at Travis AFB. Military Med. 2015;180:26-31.

14. Buja A, Lange JH, Perissinotto E, et al. Cancer incidence among male military and civil pilots and flight attendants: an analysis on published data. Toxicol Ind Health. 2005;21:273-282.

15. Wilkison BD, Wong EB. Skin cancer in military pilots: a special population with special risk factors. Cutis. 2017;100:218-220.

16. Wickman ME, Anderson NLR, Smith Greenberg C. The adolescent perception of invincibility and its influence on teen acceptance of health promotion strategies. J Pediatr Nurs. 2008;23:460-468.

17. Schreuders M, Krooneman NT, van den Putte B, et al. Boy smokers' rationalisations for engaging in potentially fatal behaviour: in-depth interviews in the Netherlands. Int J Environ Res Public Health. 2018;15:767.

18. Eastabrook S, Chang P, Taylor MF. Melanoma risk: adolescent females' perspectives on skin protection pre/post-viewing a ultraviolet photoaged photograph of their own facial sun damage. Glob Health Promot. 2018;25:23-32.

19. Killgore WD, Cotting DI, Thomas JL, et al. Post-combat invincibility: violent combat experiences are associated with increased risk-taking propensity following deployment. J Psychiatr Res. 2008;42:1112-1121.

20. Killgore WD, Kelley A, Balkin TJ. So you think you're bulletproof: development and validation of the Invincibility Belief Index (IBI) Military Med. 2010;175:499-508.

21. McGrath JM, Fisher V, Krejci-Manwaring J. Skin cancer warnings and the need for new preventive campaigns: a pilot study. Am J Prevent Med. 2016;50:E62-E63.
22. Thieden E, Philipsen PA, Sandby-Moller J, et al. Sunscreen use related to UV exposure, age, sex, and occupation based on personal dosimeter readings and sun-exposure behavior diaries. Arch Dermatol. 2005;141:967-973.

23. Holman DM, Berkowitz Z, Guy GP Jr, et al. Patterns of sunscreen use on the face and other exposed skin among US adults. J Am Acad Dermatol. 2015;73:83-92.e1.

24. Military Pay Tables \& Information. Defense Finance and Accounting Service website. Accessed December 21, 2020. https://www.dfas.mil /militarymembers/payentitlements/Pay-Tables.html

25. Schilling L, Schneider S, Gorig T, et al. "Lost in the sun”- - the key role of perceived workplace support for sun-protective behavior in outdoor workers. Am J Ind Med. 2018;61:929-938.

26. Uliasz A, Lebwohl M. Patient education and regular surveillance results in earlier diagnosis of second primary melanoma. Int J Dermatol. 2007:46:575-577.

27. MacKie RM, Hole D. Audit of public education campaign to encourage earlier detection of malignant melanoma. BMJ. 1992;304:1012-1015.

28. Berwick M, Begg CB, Fine JA, et al. Screening for cutaneous melanoma by skin self-examination. J Natl Cancer Inst. 1996;88:17-23.

29. Winterhalter $\mathrm{C}$, DiLuna $\mathrm{K}$, Bide $\mathrm{M}$, Characterization of the ultraviolet protection of combat uniform fabrics. US Army Soldier and Biological Chemical Command Soldier Systems Center technical report Natick/TR-02/006. Published January 21, 2002. Accessed December 21, 2021. https://apps.dtic.mil/dtic/tr/fulltext/u2/a398572.pdf

30. Gies P, Javorniczky J, Roy C, et al. Measurements of the UVR protection provided by hats used at school. Photochem Photobiol. 2006; $82: 750-754$

31. Stanton S. Headgear. In: Stanton S. US Army Uniforms of the Vietnam War. Stackpole Books; 1992:26-61.

32. Richmond-Sinclair NM, Pandeya N, Ware RS, et al. Incidence of basal cell carcinoma multiplicity and detailed anatomic distribution: longitudinal study of an Australian population. J Invest Dermatol. 2009;129:323-328.

33. How to select a sunscreen. American Academy of Dermatology. Accessed December 15, 2020. https://www.aad.org/sun-protection /how-to-select-sunscreen

34. Diffey BL, Grice J. The influence of sunscreen type on photoprotection. Br J Dermatol. 1997;137:103-105.

35. Xu S, Kwa M, Agarwal A, et al. Sunscreen product performance and other determinants of consumer preferences. JAMA Dermatol. 2016;152:920-927.

36. Ou-Yang H, Stanfield J, Cole C, et al. High-SPF sunscreens ( $\mathrm{SPF} \geq 70$ ) may provide ultraviolet protection above minimal recommended levels by adequately compensating for lower sunscreen user application amounts. J Am Acad Dermatol. 2012;67:1220-1227.

37. O'Connor A. Is sunscreen flammable? The New York Times. June 6, 2012. Accessed December 15, 2020. https://well.blogs.nytimes .com/2012/06/06/is-sunscreen-flammable/

38. Prevent skin cancer. American Academy of Dermatology. Accessed December 15, 2020. https://www.aad.org/public/spot-skin-cancer /learn-about-skin-cancer/prevent 